\title{
Holistic Approach to Obesity Management without Strenuous Physical Activity
}

\author{
Jain Richa*, Sharma S and Jagmohan Duggal \\ Institute of Medical Education and Research, India \\ *Corresponding Author: Jain Richa, Institute of Medical Education and Research, India.
}

Received: August 01, 2019; Published: August 19, 2019

DOI: $10.31080 /$ ASGIS.2019.02.0073

\begin{abstract}
Obesity is epidemic and the underlying cause of various lifestyle related disorders that are the scourge of mankind today. Using integrated medicine approach that combines best practices in Ayurveda and Allopathy to an method that has yielded amazing results of weight reduction coupled with health restoration. The approach involves powerful effects of Oral Food Chelation therapy and has been used in the treatment of 100 patients. What emerged as the primary preventive and curative therapy Diet control along with body mind healing.

Keywords: Obesity; Epidemic; Lifestyle
\end{abstract}

This method promotes balance and integrates body- mind-soul to provide phenomenal results right from achieving ideal weight with natural ease and maintaining it, to healing emotional pain underlying weight issues. All this and more with absolutely no side effects, supplements and reduced dependency on medicines.

Worldwide, more than 2 billion adults have been reported overweight 700 million are obese and the numbers are rapidly increasing. More than 3 billion deaths have been linked to underline causes of obesity. Unhealthy food habits, sedentary lifestyle, consumption of carbohydrate/fat-rich foods (fast food) is worsening the risk of ischemic heart disease, diabetes, etc. which is turning into an epidemic in developing countries. Incidents of obesity with increasing prevalence in women and children has doubled in the last ten years. Hormonal changes in middle years have been reported to be linked to weight gain. The problem of obesity is significantly linked with over and irregular eating patterns which can be prevented. It causes a lot financial burden on the government health care agencies Obesity has reached epidemic proportions. India is reportedly, as per recent studies, facing an epidemic of obesity with more than 135 million cases reported in a yearly basis. According to ICMRINDIAB study 2015, prevalence rate of obesity and central obesity are varies from $11.8 \%$ to $31.3 \%$ and $16.9 \%-36.3 \%$ respectively. In India, the propensity of obesity varies with age, gender, geographical environment and socio-economic status with abdominal obesity being the major risk factor for myocardial infarction. Among women, obesity is significantly higher as compared to men due to genetic and lifestyle reasons.

\section{Methodology}

A pilot study of 100 patients divided into five groups was undertaken ranging from 15- 55years.

The research methodology was adopted to treat the patients by assessing the body constitution(prakriti) an ancient Ayurvedic method that helps to establish the root cause of the case. Once the body constitution is established the imbalance of the doshas (kapha pitha vata) is determined using Nadi Shodan. After this, we use dosha specific balancing herbs, traditional condiments and food preparation methods are provided to the patients. The patient is put on a diet therapy and use of natural herbs coupled with step by step instructions on food preparation so that nutritional value of the food ingredients is present.

A calm disposition stemming out relaxation techniques is used to enhance the absorption power of the digestive system by systemic relaxation using deep breathing from diaphragm. A focused treatment at a cellular level including a mind-body connect that is combination of lifestyle changes, detoxification through panchkarma cleansing.

\section{Research findings}

The studies reveals that the BMI which was showing a standard deviation of 5.52 was observed from a mean of 31.6 before the study and after the study mean values of 28.3 were observed. This means a percentage change of $27.3 \%$ reduction was obtained which is highly significant. 
In group 1 (aged 15-25years) weight loss of 6.4kgs were obtained. In group 2(aged 26-35years) weight loss of $10.9 \mathrm{kgs}$, group $3,9.74 \mathrm{kgs}$ were obtained.

\section{Discussion}

We developed a new innovative practical approach for the assessment of the nutritional status of the patients. This combine with an improved understanding of the biochemical and metabolic process has led to focus treatment at the cellular level. This method introduces a mind body connect that helps by changing dietary patterns. This results in an emergence of new behavioral structure leading to management of chronic obesity. The results were evaluated using statistical methods and are presented in Annexure 1.

The results exhibit that an average weight loss of $9.3 \mathrm{kgs}$ in 78days was achieved in group 1. In the other age group of 46-55 years, they were able to shed $7.72 \mathrm{kgs}$ in the same time and maintain this weight loss. After the weight loss the patients were given suggestions for healthy eating to maintain this weight loss and they were monitored for 2 years.

The patients were able to overcome the compulsive food cravings that were the root cause for obesity using psychological diet counseling. Obesity is linked to maldigestion therefore the goal of the method was improving the digestive power by stimulating the mediator of the parasympathetic nervous system that travels from the brain to neatly all of the thoracic and abdominal organs and triggers a cascade it calming effects [1-8].

\section{Conclusion}

The research highlights the of Svelte that, 'Let food be your medicine lest medicine becomes your food. Billions have been spent on obesity prevention with no real cure in sight. Modern lifestyle that eulogizes a fast life coupled with fast food leads to obesity. Our unique methodology aims at lifestyle change that focuses on the root cause of the disease and tries to eliminate in a holistic manner. Another advantage of the method is the economic aspect as it involves no financial burden but uses traditional material already found in the kitchen. Further obesity is linked to a host of other lifestyle related chronic disorders that are intractable further research is required in this direction to see if this approach can be used to tackle them.

\begin{tabular}{|c|c|c|c|c|c|c|}
\hline \multicolumn{2}{|c|}{ Initial } & \multicolumn{2}{c|}{ Final } & \multirow{2}{*}{ t } & \multirow{2}{*}{ df } & \multirow{2}{*}{ Sig. (2-tailed) } \\
\cline { 1 - 4 } Mean & SD & Mean & SD & & & \\
\hline 31.6 & 5.68 & 28.3 & 5.52 & 16.7 & 89 & $.000^{* *}$ \\
\hline
\end{tabular}

Table 1: Test between initial and final BMI.

** Significant at 0.01 level $(\mathrm{t}=2.58$ )

\begin{tabular}{|l|c|c|c|}
\hline \multicolumn{1}{|c|}{ BMI } & Initial & Final & \% change BMI \\
\hline Normal & $1(1.1)$ & $28(31.1)$ & 27.3 \\
\hline OW & $44(48.9)$ & $37(41.1)$ & -0.2 \\
\hline OG1 & $26(28.9)$ & $17(18.9)$ & -0.3 \\
\hline OG2 & $10(11.1)$ & $5(5.6)$ & -0.5 \\
\hline OG3 & $9(10.0)$ & $3(3.3)$ & -0.7 \\
\hline Total & $90(100.0)$ & $90(100.0)$ & \\
\hline
\end{tabular}

Table 2: Distribution of BMI.

\begin{tabular}{|l|c|c|c|c|}
\hline AGE & Weight_Lose & $\begin{array}{c}\text { Duration_ } \\
\text { M }\end{array}$ & $\begin{array}{c}\text { Duration_ } \\
\text { W }\end{array}$ & $\begin{array}{c}\text { Duration } \\
\text { D }\end{array}$ \\
\hline $15-25$ & 6.4 & 1.9 & 7.9 & 55.5 \\
\hline $26-35$ & 10.9 & 3.1 & 13.1 & 91.5 \\
\hline $36-45$ & 9.74 & 2.4 & 10.2 & 71.4 \\
\hline $46-55$ & 7.72 & 2.6 & 11.2 & 78.1 \\
\hline$>55$ & 8.1 & 2.2 & 9.4 & 65.7 \\
\hline Total & 9.3 & 2.6 & 11.2 & 78.4 \\
\hline
\end{tabular}

Table 3: Distribution of average of weight loss according to age.

\begin{tabular}{|l|c|c|c|c|}
\hline $\begin{array}{c}\text { Final_ } \\
\text { BMI }\end{array}$ & $\begin{array}{c}\text { Weight_ } \\
\text { Lose }\end{array}$ & Duration_M & Duration_W & Duration_D \\
\hline Normal & 11.4 & 3.0 & 12.7 & 88.9 \\
\hline OW & 7.9 & 2.5 & 10.7 & 75.0 \\
\hline OG1 & 8.1 & 2.4 & 10.4 & 72.5 \\
\hline OG2 & 10.0 & 2.4 & 10.3 & 72.0 \\
\hline OG3 & 11.9 & 2.2 & 9.3 & 65.0 \\
\hline Total & 9.3 & 2.6 & 11.2 & 78.4 \\
\hline
\end{tabular}

Table 4: Distribution of average of weight loss according to Final BMI.

\begin{tabular}{|l|c|c|c|c|c|}
\hline \multicolumn{7}{|c|}{ Group Statistics } \\
\hline \multirow{2}{*}{} & Gender & N & Mean & $\begin{array}{c}\text { Std. Devia- } \\
\text { tion }\end{array}$ & $\begin{array}{c}\text { Std. Error } \\
\text { Mean }\end{array}$ \\
\hline \multirow{2}{*}{ BMI_Diff } & Male & 14 & -3.5136 & 1.78214 & .47630 \\
\cline { 2 - 6 } & Female & 76 & -3.2829 & 1.91861 & .22008 \\
\hline \multirow{2}{*}{$\begin{array}{l}\text { Weight_ } \\
\text { Lose }\end{array}$} & Male & 14 & 10.8318 & 5.34152 & 1.42758 \\
\cline { 2 - 6 } & Female & 76 & 8.9842 & 5.50033 & .63093 \\
\hline
\end{tabular}

Table 5: $\mathrm{t}$ test between male and female for BMI and weight loss. 


\begin{tabular}{|c|c|c|c|c|c|c|c|}
\hline & \multicolumn{7}{|c|}{ t-test for Equality of Means } \\
\hline & & & & & & $95 \%$ Conf & rval of the Differ- \\
\hline & $\mathbf{t}$ & df & Sig. (2-tailed) & Mean Difference & Std. Error Difference & Lower & Upper \\
\hline BMI_Diff & -.418 & 88 & .677 & -.23068 & .55232 & -1.32830 & .86694 \\
\hline Weight_Lose & 1.160 & 88 & .249 & 1.84758 & 1.59296 & -1.31810 & 5.01325 \\
\hline
\end{tabular}

Table 6: t-test for weight loss.

\begin{tabular}{|c|c|c|c|c|}
\hline \multicolumn{2}{|c|}{ Wt loses } & \multirow{2}{*}{ t } & \multirow{2}{*}{ df } & \multirow{2}{*}{ Sig. (2-tailed) } \\
\cline { 1 - 2 } Mean & SD & & & \\
\hline 9.3 & 5.48 & 16.0 & 89 & $.000^{* *}$ \\
\hline
\end{tabular}

Table 7: ** Significant at 0.01 level $(\mathrm{t}=2.58)$

\section{Acknowledement}

I thank Prof Pawandeep Singh for contribution in manuscript preparation and editing

\section{Bibliography}

1. GE Mullin., et al. "Integrative Weight Management: A Guide for Clinicians". Nutrition and Health.

2. Sharron Dalton. "Integrative Weight management". (2014).

3. Dausch J. "Determining when obesity is a disease". Journal of the American Dietetic Association 101 (2001): 293.

4. World Health Organization. Obesity and overweight (2006).

5. Newburgh LH and Johnston MW. "Endogenous obesity-a misconception". JAMA 3 (1930): 815-825.

6. NIH, NHLBI. "Clinical guidelines for the identifi cation, evaluation, and treatment of overweight and obesity in adults-the evidence report". Obesity Research 6 (1998): S51-209.

7. CMS. Decision memo for intensive behavioral therapy for obesity (CAG-00423N) (2011). http://www.cms.gov/medicarecoverage-database/details/nca-decision-memo.aspx

8. World Health Organization (2012).

\section{Volume 2 Issue 7 September 2019}

(C) All rights are reserved by Jain Richa., et al. 